\title{
Identification of mediterranean mutation in the G6PD gene on molecular level in Iraqi population.
}

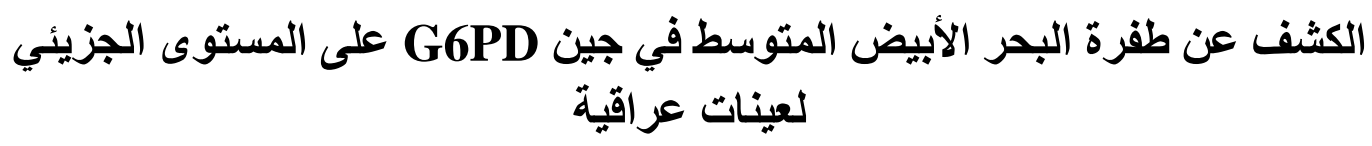

Rana A. Al-Temmemy Essam F. Al-Jumaily

Institute of Genetic Engineering and Biotechnology for postgraduate studies/ University of Baghdad

$$
\text { معهد الهندسه الور اثيه و التقنيه الاحيائيه للار اسات العليا / جامعة بغداد }
$$

\section{Abstract}

The study involved extraction of Deoxyribonucleic acid (DNA) from 71 samples of random G6PD patients and 85 samples of apparently healthy individuals from different Iraqi populations respectively, which was then amplified by polymerase chain reaction (PCR) and later subjected to digestion by restriction enzyme to create restriction fragment length polymorphism (RFLP) to enable the detection of mutation that caused G6PD deficiency namely Mediterranean (Med). The results of the current study showed that Iraqies were affected by G6PD deficiency in a percentage of $7.2 \%$ and showed that the majority of affected cases were caused by Med mutation $(95.8 \%)$. It could be concluded that Med mutation causes a serious impact on pediatric health and its the most prevalent cause of G6PD deficiency.

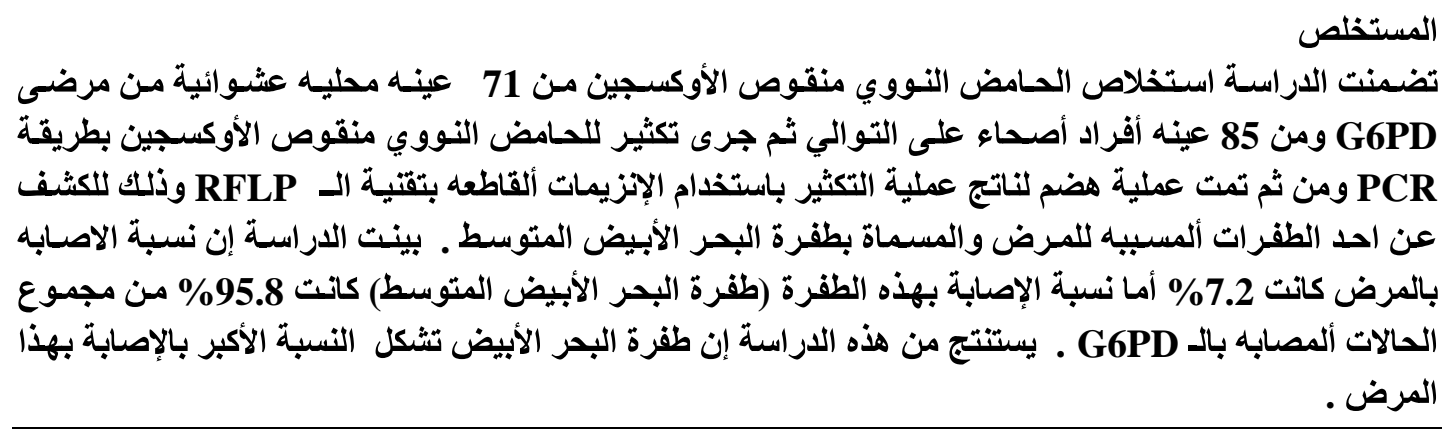

\section{Introduction}

Glucose-6-phosphate dehydrogenase (G6PD) deficiency is the most common hereditary disorder in humans and is found in people of Mediterranean, South-east Asian and African descent. The common clinical manifestations of G6PD deficiency are neonatal jaundice and acute hemolytic anemia triggered by certain drugs, infections or ingestion of 
fava beans. G6PD deficiency is a heterogeneous enzyme abnormality. There are few published population-based studies on G6PD molecular heterogeneity in the Middle East. G6PD is a "housekeeping" enzyme that performs vital functions within all cells of the body. However, within the erythrocyte which lacks a nucleus, mitochondria, and other organelles, there are certain constraints on metabolism and this enzyme has a particularly important role. G6PD catalyzes the first step of the pentose phosphate pathway (hexosemonophosphate pathway) a series of side reactions of the main glycolytic pathway in the erythrocyte and in all cells of the body.

The G6PD is one of a cluster of genes on the distal long arm of the X-chromosome (Xq28). Included in this group of genes are those for the fragile $\mathrm{X}$, hemophilia A, color vision, a putative gene for bipolar affective illness, the ABP-280 filamin gene Bornholm eye disease, clasped-thumb, mental retardation (MASA) syndrome, and dyskeratosis congenital, the gene of G-6PD contains 13 exons and is $18 \mathrm{~Kb}$ in length . The first exon contains no coding sequence and the intron between exons 2 and 3 is extraordinarily long, extending for $9,857 \mathrm{bp}[1,2]$.

G6PD Mediterranean is a deficient variant with enzyme activity that is less than $10 \%$ of the activity of G6PD B; it reaches allele frequencies of between 10 and 25 or higher in many populations in the Mediterranean region and the near and middle east. This variant is a consequence of a cytosine to thymine substitution at nucleotide number 563 resulting in a serine to phenylalanine substitution at amino acid number 188 [3].

The aim of this study was to determine the prevalence of glucose-6-phosphate dehydrogenase (G6PD) deficiency in the Iraqi population, and describe the Mediterranean (Med) mutation in the population.

\section{Materials and methods \\ Blood samples}

Blood samples were collected from seventy one random G6PD patients from different Iraqi populations were chosen during the period from March to May 2006. Patients were admitted to several Iraqi hospitals which were as follows: Azady Teaching General Hospital in Duhok, Al- Iskan teaching hospital, pediatrics hospital in Baghdad, AlKadhumia teaching hospital in Baghdad, Al-Zahra'a hospital in Diyala.

Eighty five of apparently healthy individuals from different Iraqi populations were randomly included in the study. According to the questionnaire form and the study of the patient's files the geographical and demographical distributions of both patient and control groups were recorded.

\section{DNA Extraction}

The genomic DNA was extracted from white blood cells from the G6PD deficient and apparently healthy individuals, the whole fresh blood collected in EDTA anticoagulant tubes using Wizard genomic DNA purification kits. Agrose gel (1\%) electrophoresis was adopted to confirm the presence and integrity of the extracted DNA [6].

\section{PCR/RFLP Analysis}

PCR/RFLP method was adopted to characterize mutation of the DNA samples. According to the common distribution of G6PD mutations in the neighboring countries [4,5]. 
Mediterranean mutation was chosen for molecular diagnosis in Iraq. Table (1) shows the type of mutation and its descriptive characteristics.

Table (1): Types of G6PD mutations

\begin{tabular}{|l|c|c|c|c|}
\hline G6PD variant & Origin & $\begin{array}{c}\text { Base } \\
\text { substitution }\end{array}$ & Exon no. & $\begin{array}{l}\text { Amino acid } \\
\text { substitution }\end{array}$ \\
\hline Mediterranean & Mediterranean & $563 \mathrm{C} \rightarrow \mathrm{A}$ & 6 & Ser $\rightarrow$ Phe \\
\hline
\end{tabular}

Primer sets which were selected for PCR analysis of mutations are shown in

Table (2): [7].

\begin{tabular}{|c|c|c|c|c|}
\hline Primer & Primer sequences & Length $(\mathbf{p b})$ & Temp $\left({ }^{\circ} \mathbf{C}\right)$ & TA \\
\hline G6PD-6-F & 5`ACA CAC GGA CTC AAA AGA G-3 & 19 & $62^{\circ} \mathrm{C}$ & $59{ }^{\circ} \mathrm{C}$ \\
\cline { 2 - 5 } G6PD-6-R & 5`TGG TGG GAG CAC TGC CTG -3 & 18 & $62^{\circ} \mathrm{C}$ & $59{ }^{\circ} \mathrm{C}$ \\
\hline
\end{tabular}

Optimization of PCR reaction was accomplished after several attempts; thus the following mixtures were adopted table (3).

Table (3): PCR components

\begin{tabular}{|c|c|c|}
\hline Component & Concentration & Amount $(\boldsymbol{\mu l})$ \\
\hline Deionized water & --- & 20.05 \\
\hline$*$ PCR Buffer & $10 \mathrm{X}$ & 2.5 \\
\hline $\mathrm{MgCl}_{2}$ & $50 \mathrm{mM}$ & 0.75 \\
\hline $\mathrm{dNTPs}$ & $10 \mathrm{mM}$ each & 0.5 \\
\hline Primer F & 10 picomols/ $\mu \mathrm{l}$ & 0.5 \\
\hline PrimerR & 10 picomols $/ \mu \mathrm{l}$ & 0.5 \\
\hline DNA Sample & $0.5-0.15 \mu \mathrm{g} / \mu \mathrm{l}$ & 2 \\
\hline Taq DNA Polymerase & $5 \mathrm{unit} / \mu \mathrm{l}$ & 0.2 \\
\hline Total Volume & --- & 25 \\
\hline
\end{tabular}

*The PCR buffer contains $50 \mathrm{mM} \mathrm{KCl,10} \mathrm{mM} \mathrm{Tris-HCl} \mathrm{(pH} 8.4$ at room temperature).

To reveal the hazardous cross contamination, and to check the activity of PCR components, two external controls were used: water and positive control samples. Negative \& positive results were obtained, respectively.

\section{PCR/RFLP Protocol}

\section{A-PCR Program}

To detect the mutation: Med mutation PCR programme 1 was adopted table (4): [7]. 
Table (4): PCR program for Med mutation

\begin{tabular}{|c|c|c|c|}
\hline Step & $\begin{array}{c}\text { Temperature } \\
\left({ }^{\circ} \mathbf{C}\right)\end{array}$ & $\begin{array}{c}\text { Time } \\
(\text { minutes })\end{array}$ & No. of Cycles \\
\hline $\begin{array}{c}\text { Initial } \\
\text { denaturation }\end{array}$ & 94 & 5 & 1 \\
\hline & \multicolumn{2}{|c|}{} \\
\hline Denaturation & 94 & $30 \mathrm{sec}$. & \multirow{2}{*}{32} \\
\hline Annealing & 62 & 1 & \\
\hline Extension & 72 & $45 \mathrm{sec}$. & \\
\hline Final extension & 72 & 5 & 1 \\
\hline
\end{tabular}

The PCR products and the ladder marker were examined by electrophoresis. $1 \mu \mathrm{l}$ of loading buffer plus $3 \mu \mathrm{l}$ of the product were loaded on $2 \%$ agarose gel ( $2 \mathrm{~g}$ agarose $/ 100 \mathrm{ml}$ $0.5 \mathrm{X}$ TBE buffer) and run at 80 volt for approximately 45 minutes. The gel was stained with ethidium bromide solution $(0.5 \mu \mathrm{g} / \mathrm{ml})$ for $15-30$ minutes; finally, bands were visualized on UV transiluminator and then photographed by using photo documentation system.

\section{Restriction Fragment Length Polymorphism (RFLP) Reagents}

A- Restrictions enzyme

\begin{tabular}{|c|c|c|}
\hline Restriction enzyme & Site of cut & Source \\
\hline Mbo II & $5 ` \ldots G A A G A^{*} \ldots . .$. & Moraxella bovic ATCC 10900 \\
& $3 ` \ldots C T T C T^{*} \ldots . .5$ & \\
\hline
\end{tabular}

\section{B- Polyacrylamide Gel $12 \%$}

polyacrylamide solution 40\%(12.5 ml), Ammonium Persulfate (APS) 10\%(1000 $\mathrm{\mu l}$ ), $\mathrm{N}, \mathrm{N}, \mathrm{N}, \mathrm{N}$-tetramethyl -P- phenylene diamine (TEMED) $10 \mu \mathrm{l}$.

\section{Sample Preparation of RFLP}

Reaction component contain PCR Product (1-2 $\mu \mathrm{l})$, Restriction enzyme buffer 10X (1 $\mu \mathrm{l})$, Restriction enzyme $(0.2 \mu \mathrm{l})$, D.W $(7.8-6.8) \mu \mathrm{l}$, the reaction component was gently mixed by pipetting, and then the tube was closed and centrifuged for a few seconds. Incubated at the optimum temperatures $37^{\circ} \mathrm{C}$ for $(4-18) \mathrm{h}$. After that proteinase $\mathrm{K}$ was incubated at $37^{\circ} \mathrm{C}$ for $2 \mathrm{hr}$. The samples $(10 \mu \mathrm{l})$ were applied to the wells of the gel.

\section{Experimental controls}

Experimental controls are necessary to identify, understand and explain problems or inconsistencies in results. The following controls are commonly used in parallel with restriction enzyme (RE) digests:

Uncut DNA, Positive control of PCR product (normal DNA), Negative control of PCR product (mutant DNA) and Negative control (RE without DNA) 


\section{Running Condition}

Electrophoresis was performed under the following conditions, voltage $120 \mathrm{~V}$, current 20 $\mathrm{mA}$, temperature $37^{\circ} \mathrm{C}$, and it lasted for five hours or until the bromophenol blue reached the end of the gel.

\section{Staining Solution}

Solution I: Ethanol (96\%) $20 \mathrm{ml}$, acetic acid1.5 ml, D.W179 ml, Solution II: $\mathrm{AgNo}_{3} 0.1$ gm, D.W100 ml, Solution III: NaOH (1.5\%) 200 ml, Formaldehyde $180 \mu \mathrm{l}$

\section{* Protocol}

The gel was transferred to clean staining tray and fixed in $200 \mathrm{ml}$ in solution 1 for 5 minutes by gentle agitation. The gel was kept in solution II for 15 minute with shake then washed 2 times in distilled water. The gel was stained in solution III for 15 minutes with shake (until the band appeared) then washed 2 times in distilled water.

\section{Results and Discussion}

Blood samples were subjected to DNA isolation procedure within 2-24 hours of aspiration. The band integrity and DNA concentration were found to be different according to the amount of yielded genomic DNA and its purity which depended on the amount of WBCs in the blood samples Figure (1). In addition, the DNA isolation should be applied to fresh blood sample as soon as possible.

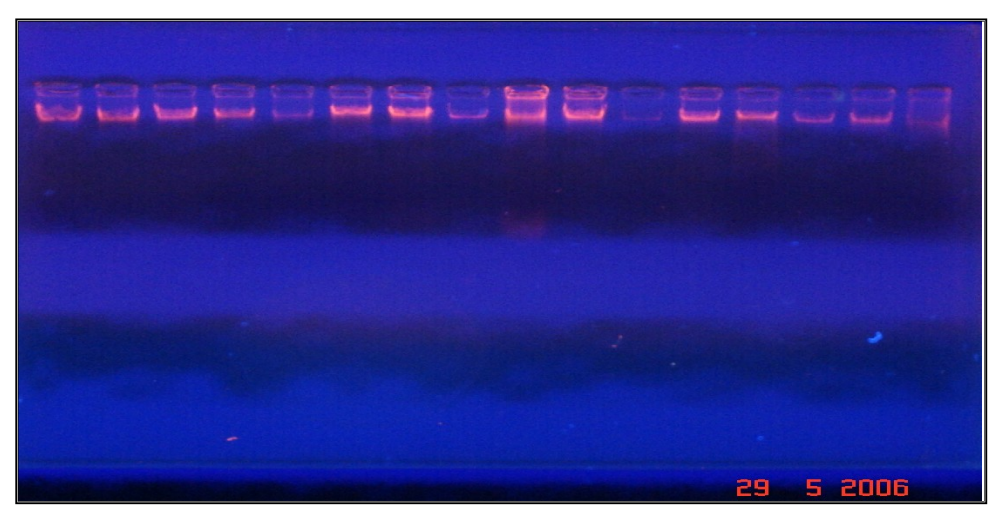

Fig (1): Chromosomal DNA bands on $1 \%$ agarose gel at 70 voltages for one hour

PCR analysis for G6PD was accomplished for the 71 samples of patients and 86 controls. Med mutation was detected by characteristic band patterns on 2\% Agarose.

The results of the current study reveal that mutation samples were amplified by PCR through the use of specific primers and it is shown that the PCR products.For Med mutation single band of $263 \mathrm{bp}$ was observed Figure (2) from PCR products of Med mutation turned on a $2 \%$ agarose gel. Lane 1: DNA marker (100 bp). 


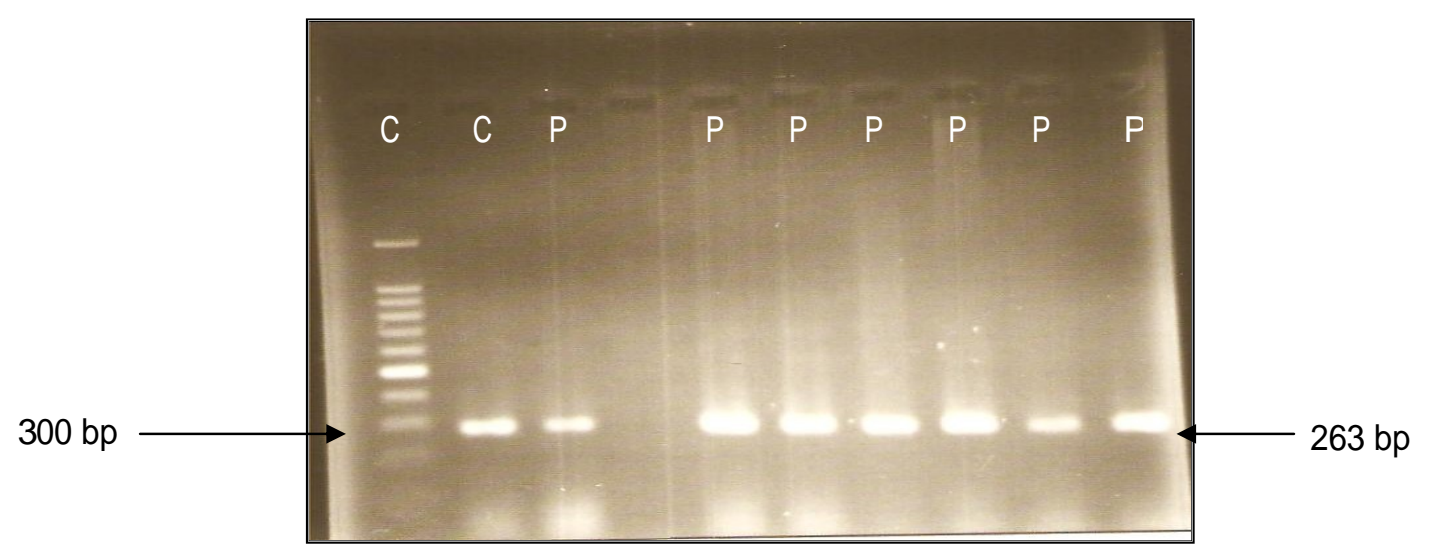

Fig (2): PCR product for med mutation. Bands run on Agrose 2\%.C: control, p: patient

The G6PD-Med mutation at base position 563 creates an Mbo II site in exon 6 of the G6PD gene. The results of successful PCR amplification were treated by digestion with Mbo II restriction enzyme (mixture incubated at $37^{\circ} \mathrm{C}$ overnight). After the end of the digestion period, DNA bands were separated on polyachrylamide $12 \%$ and visualized using silver staining. The normal samples showed $263 \mathrm{bp}$ fragments, and the mutant samples showed $100 \mathrm{bp}$ and $150 \mathrm{bp}$ fragments. In Heterozygote samples, $263 \mathrm{bp}, 100 \mathrm{bp}$ and $150 \mathrm{bp}$ fragments were seen. The G6PD Mediterranean genotype constituted 68 cases of 71 deficient subjects in a percentage of $(95.8 \%)$ Figure (3)

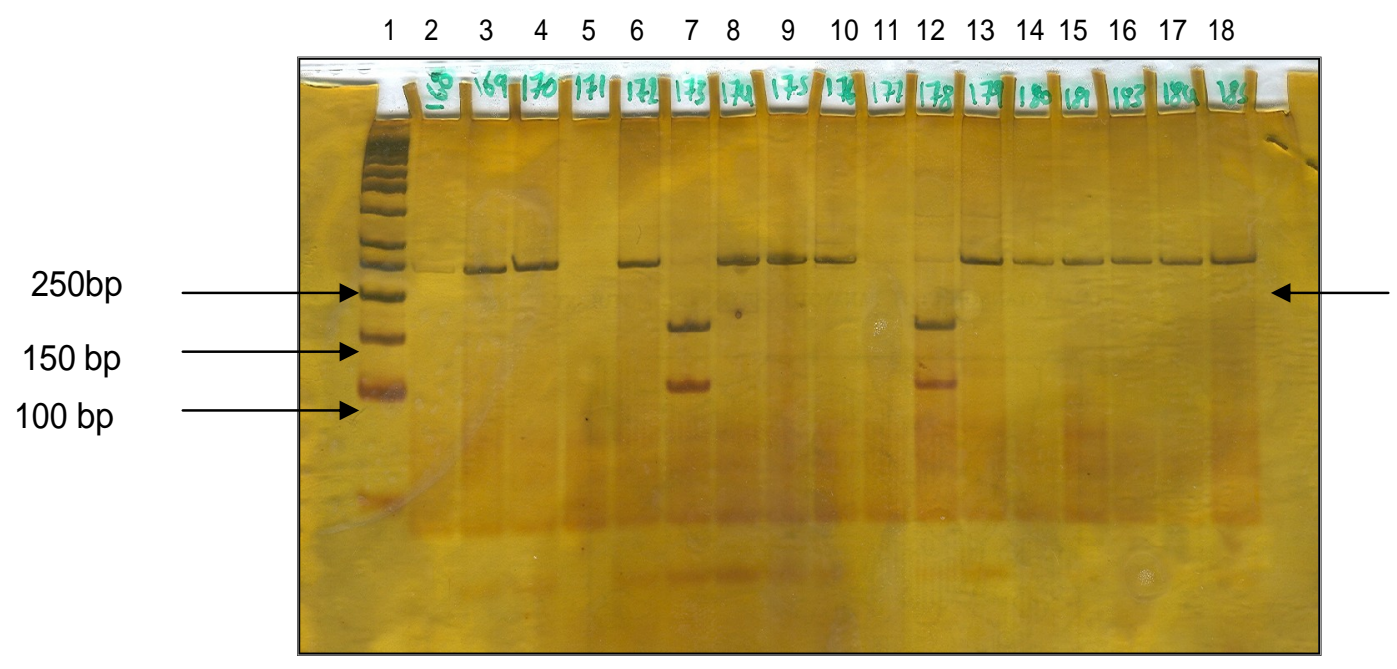

$263 \mathrm{bp}$

Fig (3): Restriction enzyme analysis of G6PD Mediterranean mutation. Lane 1: size markers, lanes 2-6: normal undigested, lane 7 and 12: $M b o I I$ digestion of samples with G6PD Mediterranean, lanes 13-18: normal undigested.

The possibility that Mediterranean type of G6PD deficiency is a composite of several mutants was first raised by [8] who noticed diverse kinetic behavior in the G6PD of 16 Greek males who were severely deficient in that enzyme. In the absence of family data, no definitive genetic interpretations of these observations could be made, but the authors 
indicated that if the observed diversity was due to genetic heterogeneity, at least three G6PD variants would be required to account for their findings [9].

Based on biochemical and genetic analyses of a number of samples enrolled in multiple studies, it had been assumed that the common type present in the Eastern Province is G6PD Mediterranean. The molecular basis of G6PD Mediterranean was found to be due to a point mutation $(\mathrm{C} \rightarrow \mathrm{T})$ at nucleotide 563 leading to a Serine to phenylalanine replacement at amino acid position 188 [10]. This was found to be associated with another but silent mutation at nucleotide 1311 in those from the Mediterranean region and Middle East but not in those from India. This does not support the original concept of single origin of this variant but suggests a possible independent origin of G6PD Mediterranean in the middle East and Europe from that of Indian subcontinent [11.12]. Recently, no other variants have been reported for this population. However, studies in other parts of the world have shown that a gene flow due to population migration is common. The analysis of a large number of G6PD-deficient samples revealed that G6PD Mediterranean accounted for $84 \%$ of the samples investigated. Considering the geographic location of Saudi Arabia, it is not surprising that G6PD Mediterranean variant predominates [5].

These results are in marked consistency with the results of the present study and [5] suggested geographical location as a determinant factor for explaining the similarity, the researcher can rely on the same reason to elucidate the similarity with the above mentioned results.

In Turkey, molecular studies of G6PD deficiency are very rare and extremely limited in scope. Among 50 G6PD deficient male subjects from various parts of Turkey, the Mediterranean mutation was found in about $80 \%$ [13]. In Antalya province, among 20 families, the Mediterranean mutation was found in all the families [14]. It was reported that, the Mediterranean mutation was found in $79 \%$, which is essentially in line with the figure reported in the general population of Turkey and in Antalya province. These findings suggest that the most common variant of G6PD deficiency found in most parts of Turkey is the Mediterranean mutation [15]. Furthermore, in Iran, the Mediterranean variant showed a high prevalence, and it was estimated to be about 75.4\% [4].

In their independent study which was conducted in Jordan [16] utilized the PCR amplification and sequencing reaction to determine the type of variants that cause G6PD within their country, they found six different G6PD mutations and 53.3\% of the studied samples were of the Mediterranean mutation. The above mentioned results show an inconsistency with the results of the current study which might be explained by the observation that the lower prevalence of the G6PD Mediterranean mutation and the finding of six different mutations in a relatively small population reflect the considerable genetic heterogeneity of the Jordanian population.

Screening for the spectrum of G6PD mutations in ethnic Kuwaitis revealed that G6PD Mediterranean is the most common mutation $(74.2,72.9) \%$ followed by G6PD A ${ }^{-}(12.4$, $14.3) \%$ reported by $[7,17]$, respectively. These results are consistent with the findings among other Arabic populations in the region [18], and inconsistent with the results of the present study. The absence of any Negro patient, where $\mathrm{A}^{-}$variant is likely to be encountered, in the samples enrolled in the current study might elucidate the discrepancy of the results. 
It was shown that 2 G6PD-deficient mutations $(563 \mathrm{C} \rightarrow \mathrm{T}$ and $202 \mathrm{G} \rightarrow \mathrm{A}$ ) are present in the Kuwaiti population at polymorphic frequency. The frequencies of both alleles seem to be lower in males than in females; however, these differences are not statistically significant [17]. Nevertheless, at least theoretically, the high rate of consanguineous marriages in the Arabs and selective advantages of G6PD heterozygotes against malaria may result in unequal allelic frequencies in males and females. It is widely accepted that accumulation of G6PD-deficient mutations observed in some populations is due to a selective advantage of such variants against malaria [10, 19].

The Mediterranean mutation was found to be the most common mutation causing G6PD deficiency in the UAE [20, 21]. Other mutations detected include the African mutation and G6PD-Aures (148T) [20].

Threehundred tested males for G6PD deficiency and identified $2(0.67 \%)$ who were G6PD deficient [22]. Both subjects had the 563C-T substitution of G6PD Mediterranean (Ser188 to Phe), and both had the silent $1311 \mathrm{C} \rightarrow$ T change. A similar second change has been described in persons living in Mediterranean countries and the Middle East countries. However, the form of G6PD Mediterranean found in India and Pakistan has no replacement at nucleotide 1311. Thus, the 2 subjects in Kathmandu, Nepal, would be closer to people in the Middle East countries than people in India.

Presented data suggesting from [23] that coexistence of Mediterranean type G6PD deficiency with the AT insertion polymorphism of the promoter of the UGT1A1 gene, which is associated with Gilbert syndrome in adults, is responsible for the development of neonatal hyperbilirubinemia. This is the most devastating clinical consequence of G6PD deficiency; it can be severe and result in kernicterus or even death. It was also found that neither G6PD deficiency nor the polymorphism of UDP glucuronosyltransferase alone increased the incidence of neonatal hyperbilirubinemia, but in combination they did so Glucose-6-phosphate dehydrogenase deficiency is a major public health problem. Geographically, it is extremely heterogeneous among Iraqi population and Mediterranean type is the most frequent G6PD mutations.

\section{References}

1. Mandel, J. L.; Monaco, A. P.; Nilson, D. L.; Schlessinger, D. and Willerd, H. (1992) . Genome Analysis and the Human X chromosome. Science 258: 103-109.

2. Takizawa, T.; Yoneyama, Y.; Miwa, S. and Yoshida, A. (1987). Genomics 1: 228-231.

3. Cappellini, M. D.; DiMontemuros, F. M.; Bellis, G.; Debernardi, S.; Dottic, C. and Fiorelli, G. (1996). MultipleG-6-PD mutation is associated with a Clinical and Biochemical phenotype similar to that of G-6-PD Mediterranean. Blood, 87 (9): 39533958.

4. Noori-Daloii, M. R.; Hajebrahimi, Z.; Najafi, L.; Mesbah-Namin, S. A.; Mawjoodi, A.; Ganji, S. M; Yekaninejed, M. S. and Sanati, M. H.(2007). Acomprehensive study on the major mutations in glucose-6-phosphate dehydrogenase deficiency polymorphic variants identified in the coastal provinces of Caspian Sea in the north of Iran. 40: 699704. 
5. Al-Ali, A. K. ; Al-Mustafa, Z. H. ; Al-Madan, M. ; Qaw, F. and Al-Ateeq, S.(2002). Molecular characterization of Glucose-6-Phosphate Dehybrogenase Deficiency in the Eastern province of Saudi Arabia. Clin. Chem. Lab. Med. 40(8):814-816.

6. Sambrook,J.; Fritsch,E.F.; and Maniatis,T. (1989). Molecular cloning: A laboratory manual. $2^{\text {nd }}$ edition, Cold spring harbor laboratory press, cold spring Harbor, New York.

7. Al-Fadhli, S.; Kaaba, S.; El-shafey, A.; Salim, M.; Al-Awadi, A. and Bastaki, L. (2005). Molecular Characterization of Glucose-6-Phosphate Dehydrogenase Gene Defect in the Kuwaiti Population. Arch. Pathol. Lab. Med. 129: 1144-1147.

8. Kirkman, H. N.; Doxiadis, S. A. ; Valaes, T. ; Tassopoulos, N. and Brinson, A. G. (1965). Diverse characteristics of glucose-6phosphate dehydrogenase from Greek children. J. Lab Clin. Med. 65: 212-218.

9. Stamatoyannopoulos, G.; Voigtlander, V.; Kotsakis, P.; and Akrivkis, A.(1971). Genetic Diversity of the "Mediterranean" Glucose- 6-Phosphate Dehydrogenase Deficiency Phenotype. The Journal of Clinical Investigation 50:1253-1261.

10. Vulliamy, T.; Mason, P. and Luzzatto, L. (1992). The molecular basis of glucose-6phospate dehydrogenase deficiency. Trends Genet 8:138-143.

11. Kurdi-Haidar, B.; Mason, P.J.; Berrebi, A.; Ankra-Badu, G.; Al-Ali, A. and Oppenheim, A.(1990). Origin and spread of the glucose-6- phosphate dehydrogenase variant (G6PD-Mediterranean) in the Middle East. Am J Hum Genet 4:1013-1019.

12. Al-Ali, A.K. (1996).common G6PD variant from Saudi population and its prevalence. Ann Saudi Med 16(6):654-656.

13. Oner, R.; Gumruk, F. and Acar, C.(2000). Molecular characterization of glucose- 6phosphate dehydrogenase deficiency in Turkey. Haematologica 85: 320-321.

14. Bagci, H.; Canatan, D. and Samakoglu, S.(1998).Erythrocyte glucose-6-phosphate dehydrogenase deficiency in Antalya, Turkey: A study on the 563 mutation of G6PD gene. Br J Haematol.102: 297-301.

15. Keskin, N.; Ozdes, I.; Keskin, A.; Acikbas, I. and Bagci, H.(2002). Incidence and molecular analysis of glucose-6-phosphate dehydrogenase deficiency in the province of Denizli, Turkey. Med Sci Monit 8(6): 453-456.

16. Karadsheh, N. S.; Moses, L.; Ismail, S. I.; Devaney, J. M. and Hoffman, E. (2005). Molecular heterogeneity of glucose-6-phosphate dehydrogenase deficiency in Jordan. The hematology journal. 90(12): 1693-1694.

17. Samilchuk, E.; Souza, B. and Al-Wadi, S. (1999). Population study of common Glucose-6-Phosphate Dehydrogenase mutation in Kuwait. Hum Hered, 49: 41- 44.

18. Al-Hazmi, M. A. and Warsy, A. S. (1986). Glucose-6-phosphate dehydrogenase polymorphism in the Saudi population. Hum Hered. 36: 24-30.

19. 19-Beutler, E. (1994). G-6-PD Deficiency. Blood, 84(11): 3613-3636.

20. Bayoumi, R.A.; Nur-E-Kamal, M.S.A.; Tadayyon, M.; Mohamed, K.K.A.; Mahboob, B.H.; Qureshi, M.M.; Lakhani, M.G.; Ausiad, M.O.; Kaeda, J.; Vullamy, T.J. and Luzzatto, L.(1996): Molecular characterization of erythrocyte glucose-6-phosphate dehydrogenase defi ciency in Al Ain district, United Arab Emirates. Hum Hered 46: $136-141$. 
21. Abdulrazzaq,Y. M.; Micallef, R.; Qureshi, M. M.; Dawodu, A.; Ahmed, I.; Khidr, A.; Bastaki, S. M. A.; Al-Khayat, A. I. and Bayoumi, R. A.(1999). Diversity in expression of glucose-6-phosphate dehydrogenase deficiency in females. Clinical Genetics. 55:1319.

22. Matsuoka, H.; Jichun, W.; Hirai, M.; Yoshida, S.; Arai, M.; Ishii, A. and Baral, M. P. (2003). Two cases of glucose-6-phophate (sic) dehydrogenase-deficient Nepalese belonging to the G6PD Mediterranean-type, not India-Pakistan sub-type but Mediterranean-Middle East sub-type. J. Hum. Genet. 48: 275-277.

23. Kaplan. M.; Renbaump, P.; Levy-lahad, E.; Hammerman, C.; Levey- Lahad, A. and Beutlur, E. (1997). Gilbert syndrome and glucose-6-phosphate dehydrogenase deficiency: A dose-dependent genetic interaction crucial to neonatal hyperbilirubinemia. Proc. Natl. Acad. Sci. USA 94: 12128-12132. 